\title{
Carotid arterial cannulation: removing the risk with ultrasound?
}

\author{
Calvin Thompson, MD $\cdot$ Tammy Barrows, MD
}

Received: 12 January 2009/Accepted: 6 March 2009/Published online: 24 April 2009

(c) Canadian Anesthesiologists' Society 2009

\section{To the Editor,}

The rate of injury to the carotid artery using landmark techniques for central venous catheterization (CVC) of the internal jugular vein has been estimated to be 5.9\%. ${ }^{1}$ Most punctures likely go unreported. Cannulation of the carotid artery occurs less frequently, at a rate estimated as being between $0.0995 \%$ and $0.775 \%{ }^{2}$ The literature supports the use of ultrasound (US) guidance for CVC via the internal jugular approach. Compared to landmark techniques, a reduction in the risk of carotid injury and cannulation has been demonstrated with the use of $\mathrm{US}^{3}{ }^{3}$ leading national organizations (National Institute for Clinical Excellence [UK], Agency for Healthcare Research and Quality [USA]) to recommend US guided internal jugular CVC insertion. We describe an intraoperative carotid artery puncture during attempted internal jugular venous cannulation, which occurred despite the use of US.

A 34-year-old male with chronic renal failure had a CVC placed for perioperative monitoring during renal transplantation. The right jugular approach was used with US guidance oriented in the transverse view. A puncture of the carotid artery by the $18 \mathrm{G}$ needle was identified by color and pulsatility. The needle was withdrawn and pressure applied. The next attempt, also with US, resulted in a puncture of a vessel that was identified as a vein because of the dark non-pulsatile blood aspirated through the needle. Next, a multi-lumen 7 Fr catheter was inserted, and arterial cannulation was identified by connecting the catheter to a pressure transducer. The catheter was withdrawn and pressure applied. A non-pulsatile hematoma developed, and further attempts at CVC were abandoned. Due to the

C. Thompson, MD $(\varangle) \cdot$ T. Barrows, MD

The Ottawa Hospital, Ottawa, Canada

e-mail: cthompson@ottawahospital.on.ca; calvint@rogers.com hematoma, the patient required brief postoperative ventilation. A postoperative Doppler exam of the carotid artery was normal.

The use of an US technique does not remove all risk inherent with CVC insertion. Methods are not standardized, and we believe many practitioners use the US technique only to locate and puncture the internal jugular vein, and then they discontinue using the method. ${ }^{4}$ Movement may still occur with migration of the needle outside the vein during the Seldinger technique, resulting in wire malposition. We suggest that re-imaging the vein and confirming the presence of the guidewire in the internal jugular vein prior to dilation might prevent catheter placement into the carotid artery (Fig. 1).

Emphasis of US is to prevent injury to the carotid artery; however, how should these events be managed when identified? The traditional response has been removal of the needle or catheter and direct pressure at the site. ${ }^{2,5}$ Is this "cross your fingers" approach appropriate? Reviews of management of carotid artery cannulation suggest surgical management is the safest and most effective treatment. Guilbert et al. ${ }^{5}$ reported that $47 \%$ of patients who were treated by immediate removal of the catheter and direct external pressure suffered major complications, including two deaths, whereas surgical exploration or removal by endovascular approaches avoided major complications. Clinically, one problem is the difficulty in precisely predicting the site of catheter entry into the artery by examining the skin entry site. ${ }^{2}$ Local pressure to stop bleeding may not be effective and may result in complications. Surgical consultation may be suggested by these reviews, but there may be differences of opinion among surgeons regarding optimal management in these cases.

Thus, there should be a clear management plan in place prior to the occurrence of carotid artery injury. An 
Fig. 1 Ultrasound images of guidewire correctly placed within the internal jugular vein. Longitudinal view (left) and transverse view (right)

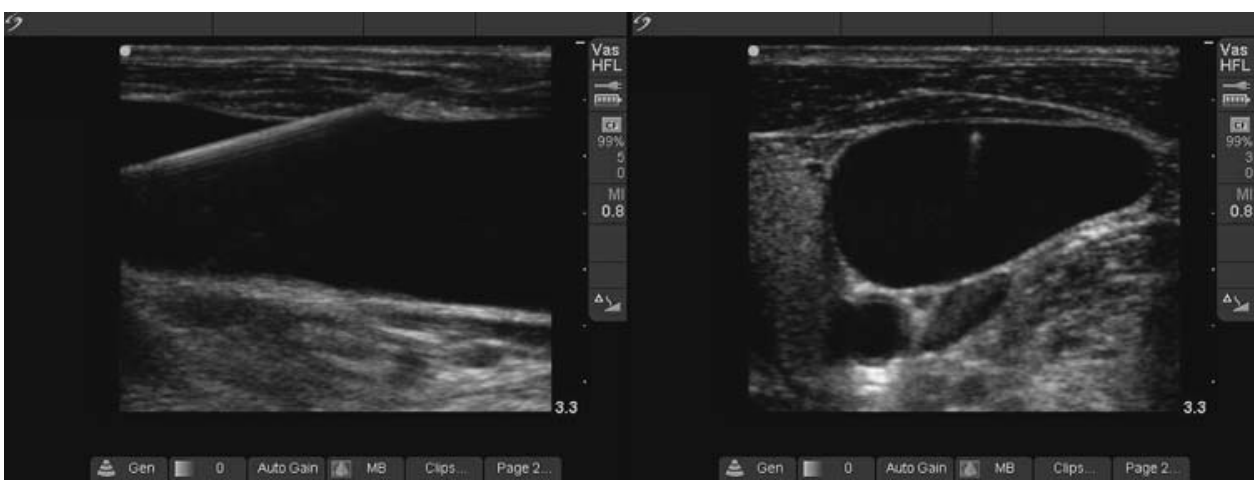

institutional consensus should be developed after discussion with vascular and general surgery and radiology. Following carotid artery injury, hematoma or neurological status should be aggressively monitored, and a Doppler exam of the carotid artery should be considered to rule out thrombus, fistula, or aneurysm. We should be aware that US techniques do not remove all risks associated with CVC insertion.

\section{Financial/Competing interests None.}

\section{References}

1. Reuber M, Dunkley LA, Turton EP, Bell MD, Bamford JM. Stroke after internal jugular venous cannulation. Acta Neurol Scand 2002; 105: 235-9.
2. Shah PM, Babu SC, Goyal A, Mateo RB, Madden RE. Arterial misplacement of large-caliber cannulas during jugular vein catheterization: case for surgical management. J Am Coll Surg 2004; 198: 939-44.

3. Wigmore TJ, Smythe JF, Hacking MB, Raobaikady R, MacCallum $N S$. Effect of the implementation of NICE guidelines for ultrasound guidance on the complication rates associated with central venous catheter placement in patients presenting for routine surgery in a tertiary referral centre. Br J Anaesth 2007; 99: 662-5.

4. Feller-Kopman D. Ultrasound-guided internal jugular access: a proposed standardized approach and implications for training and practice. Chest 2007; 132: 302-9.

5. Guilbert MC, Elkouri S, Bracco D, et al. Arterial trauma during central venous catheter insertion: case series and proposed algorithm. Can J Anesth 2007; 54: 44538 (abstract). 